\title{
Inequality and Growth: Why Differential Fertility Matters*
}

\author{
David de la Croix \\ FNRS, IRES \& CORE \\ Matthias Doepke \\ UCLA
}

September 2002

\begin{abstract}
We develop a new theoretical link between inequality and growth. In our model, fertility and education decisions are interdependent. Poor parents decide to have many children and invest little in education. A mean-preserving spread in the income distribution increases the fertility differential between the rich and the poor, which implies that more weight gets placed on families who provide little education. Consequently, an increase in inequality lowers average education and, therefore, growth. We find that this fertility-differential effect accounts for most of the empirical relationship between inequality and growth.
\end{abstract}

\footnotetext{
*We thank Costas Azariadis, Harold Cole, Roger Farmer, Gary Hansen, Lee Ohanian, Martin Schneider, the editor, and two anonymous referees for helpful comments and suggestions. We also benefited from discussions with seminar participants at the Stockholm School of Economics, the SED Meeting in Stockholm, USC, GREQAM, the University of Namur, and the European University Institute. David de la Croix acknowledges financial support from the Belgian French-speaking community (grant ARC 99/04-235) and of the Belgian Federal Government (grant PAI P5/10). Matthias Doepke acknowledges support from the NSF and the UCLA Academic Senate. David de la Croix: National Fund for Scientific Research (Belgium), IRES \& CORE, Université catholique de Louvain, Place Montesquieu 3, B-1348 Louvain-la-Neuve, Belgium. E-mail address: delacroix@ires.ucl.ac.be. Matthias Doepke: Department of Economics, UCLA, 405 Hilgard Ave, Los Angeles, CA 90095-1477. E-mail address: doepke@econ.ucla.edu.
} 


\section{Introduction}

How does the income distribution of a country affect its rate of economic growth? We argue that to answer this question, it is essential to account for the fertility differential between the rich and the poor. Our argument is simple: the fertility differential matters because it affects the accumulation of human capital. Assuming that we identify human capital with education, future human capital is a weighted average of the education of today's children from families in different income groups, with the weights given by income-specific fertility rates. Poor parents tend to have many children and provide little education. If the fertility differential between the rich and the poor is large, more weight is put on children with little education, which lowers average education. The fertility differential, in turn, is a function of the income distribution. If the differential increases with inequality, countries with higher inequality will accumulate less human capital, and therefore grow slower.

We develop a growth model which captures this channel from inequality to growth. Our model is related to Glomm and Ravikumar (1992), who analyze the effects of public versus private education on growth in a model with fixed fertility. We use a similar overlapping-generations framework, but model endogenous fertility decisions along the lines of Becker and Barro (1988). Both fertility and education are thus chosen endogenously. Parents face a quality-quantity tradeoff in their decision on children, and we show that education increases with the income of a family (richer families can afford more education), while fertility decreases with income (the time cost of child rearing is high for rich parents). The aggregate behavior of the model depends on the initial distribution of income. Other things being equal, we find that economies with a less equitable income distribution have higher fertility differentials, accumulate less human capital, and have a lower rate of economic growth. A calibrated version of our model with endogenous fertility choice shows that this effect is quantitatively important and accounts for most of the empirical relationship between inequality and growth. In contrast, if we impose fertility to be constant across income groups, the effects of inequality on human capital and growth are small.

We also analyze the dynamic properties of the model. Since in our dynastic framework a period corresponds to one generation, the dynamics of the model are to be interpreted as changes which occur over a horizon of a century or more. Here we 
find that the predictions of the model are similar to broad patterns of development observed in industrializing countries in the 19th and 20th centuries. For realistic parameter values, the interaction of fertility and education decisions gives rise to nonmonotone behavior in inequality and fertility: both variables rise initially, and later start to fall. In other words, the model generates both a Kuznets curve and a demographic transition. Thus, in addition to accounting for the cross-sectional relationship between inequality and growth, the model generates plausible implications for the dynamic interaction of inequality, fertility, and growth over long time horizons.

The relationships between inequality, differential fertility, and growth postulated by the model are supported by empirical results. Kremer and Chen (2000) examine the relationship between inequality and differential fertility. Using cross-country data, they find that more inequality tends to be associated with larger fertility differentials within a country. This supports the first part of our hypothesis, linking inequality to differential fertility. To examine the second part of our hypothesis, the link from differential fertility to growth, we add a differential-fertility variable to a standard growth regression and find large significant effects of differential fertility on growth. In the same regressions, the direct effect of inequality as measured by Gini coefficients is insignificant, once differential fertility is included.

The majority of the existing literature on inequality and growth concentrates on channels where inequality affects growth through the accumulation of physical capital (see Bénabou (1996)). To our knowledge, Althaus (1980) is the only existing model that analyzes the effects of differential fertility on growth. However, in Althaus' model fertility differentials are exogenously given, and the role of human capital is not considered. Endogenous fertility differentials arise in Dahan and Tsiddon (1998), but since their model does not allow for long-run growth, the analysis concentrates on the transition to the steady state. In Galor and Zang (1997), inequality affects growth through its effect on overall fertility and human capital. Financial market imperfections play a crucial role in their analysis. Morand (1999) has a model of inequality and fertility in which the sole motive for fertility is old-age support. He concentrates on the possibility of poverty traps when the initial level of human capital is too low. Our paper also relates to empirical studies of the growth-inequality relationship such as Barro (2000) and Perotti (1996). Both Barro and Perotti find that demographic variables are important for understanding the growth effects of the income distribution, 
but once again differential fertility is not considered directly.

In the following section, we introduce the model. Section 3 presents theoretical results on the quality-quantity tradeoff and the long-run dynamics of the model. In Section 4 we calibrate and simulate the model to assess the quantitative importance of the differential-fertility channel, and to examine the implications for the dynamic evolution of inequality, fertility, and growth. Empirical evidence is discussed in Section 5, and Section 6 concludes.

\section{The Model Economy}

Consider an economy that is populated by overlapping generations of people who live for three periods: childhood, adulthood, and old age. Time is discrete and goes from 0 to $\infty$. All decisions are made in the adult period of life. People care about adult consumption $c_{t}$, old-age consumption $d_{t+1}$, their number of children $n_{t}$, and the human capital of children $h_{t+1}$. The utility function is given by:

$$
\ln \left(c_{t}\right)+\beta \ln \left(d_{t+1}\right)+\gamma \ln \left(n_{t} h_{t+1}\right)
$$

The parameter $\beta>0$ is the psychological discount factor and $\gamma>0$ is the altruism factor. The role of old-age consumption is to provide a motive for savings and therefore generate an endogenous supply of capital. Notice that parents care about both the quantity $n_{t}$ and the quality $h_{t+1}$ of their children. Raising one child takes fraction $\phi \in(0,1)$ of an adult's time. An adult has to choose a consumption profile $c_{t}$ and $d_{t+1}$, savings for old age $s_{t}$, number of children $n_{t}$, and schooling time per child $e_{t}$. The budget constraint for an adult with human capital $h_{t}$ is:

$$
c_{t}+s_{t}+e_{t} n_{t} w_{t} \bar{h}_{t}=w_{t} h_{t}\left(1-\phi n_{t}\right),
$$

where $w_{t}$ is the wage per unit of human capital. We assume that the average human capital of teachers equals the average human capital in the population $\bar{h}_{t}$, so that education cost per child is given by $e_{t} w_{t} \bar{h}_{t}$. The assumption that teachers instead of parents provide education is crucial for generating fertility differentials. It implies that the cost of education is fixed and does not depend on the parent's wage. Educa- 
tion is therefore relatively expensive for poor parents. In contrast, since raising each child takes a fixed amount of the parent's time, having many children is more costly for parents who have high wages. Parents with high human capital and high wages therefore substitute child quality for child quantity and decide to have less children with more education.

The only friction in the model is that children cannot borrow to finance their own education. Instead, education has to be paid for by the parents. This assumption is made in most studies of the joint determination of fertility and education. In the real world, children generally do not finance their own education (at least up to the secondary level).

The budget constraint for the old-age period is:

$$
d_{t+1}=R_{t+1} s_{t}
$$

$R_{t+1}$ is the interest factor. The human capital of the children $h_{t+1}$ depends on human capital of the parents $h_{t}$, average human capital $\bar{h}_{t}$, and education $e_{t}$ :

$$
h_{t+1}=B_{t}\left(\theta+e_{t}\right)^{\eta}\left(h_{t}\right)^{\tau}\left(\bar{h}_{t}\right)^{\kappa} .
$$

Here the parameter $\tau \in[0,1]$ captures the intergenerational transmission of human capital within the family, whereas $\kappa \in[0,1-\tau]$ represents externalities at the community or society level. Alternatively, $\mathcal{\kappa}$ can be interpreted as measuring the effect of the quality of schooling, since $\bar{h}$ is the average human capital of teachers. The efficiency parameter $B_{t}$ increases deterministically at a constant rate:

$$
B_{t}=B(1+\rho)^{(1-\tau-\kappa) t} .
$$

The parameters satisfy $B, \theta>0$ and $\eta \in(0,1)$. The presence of $\theta$ guarantees that parents have the option of not educating their children, because even with $e_{t}=0$ future human capital remains positive. As in Rangazas (2000), equations (3)-(4) are compatible with endogenous growth for $\kappa=1-\tau$, and with exogenous growth otherwise. We will later explore the implications of exogenous versus endogenous growth for the long-run behavior of the economy.

Production of the consumption good is carried out by a single representative firm 
which operates the technology:

$$
Y_{t}=A K_{t}^{\alpha} L_{t}^{1-\alpha}
$$

where $K_{t}$ is aggregate capital, $L_{t}$ is aggregate labor supply, $A>0$ and $\alpha \in(0,1)$. Physical capital completely depreciates in one period. The firm chooses inputs by maximizing profits $Y_{t}-w_{t} L_{t}-R_{t} K_{t}$.

Human capital is distributed over the adult population according to the distribution function $F_{t}\left(h_{t}\right)$. Total population $P_{t}$ evolves over time according to:

$$
P_{t+1}=P_{t} \int_{0}^{\infty} n_{t} \mathrm{~d} F_{t}\left(h_{t}\right)
$$

and the distribution function of human capital, $F_{t}(h)$ evolves according to:

$$
F_{t+1}(h)=\frac{P_{t}}{P_{t+1}} \int_{0}^{\infty} n_{t} I\left(h_{t+1} \leq h\right) \mathrm{d} F_{t}\left(h_{t}\right) .
$$

Here $I(\cdot)$ is an indicator function, and it is understood that the choice variables $n_{t}$ and $h_{t+1}$ are functions of the individual state $h_{t}$. Average human capital $\bar{h}_{t}$ is given by:

$$
\bar{h}_{t}=\int_{0}^{\infty} h_{t} \mathrm{~d} F_{t}\left(h_{t}\right)
$$

The market-clearing conditions for capital and labor are:

$$
K_{t+1}=P_{t} \int_{0}^{\infty} s_{t} \mathrm{~d} F_{t}\left(h_{t}\right)
$$

and:

$$
L_{t}=P_{t}\left[\int_{0}^{\infty} h_{t}\left(1-\phi n_{t}\right) \mathrm{d} F_{t}\left(h_{t}\right)-\int_{0}^{\infty} e_{t} n_{t} \bar{h}_{t} \mathrm{~d} F_{t}\left(h_{t}\right)\right] .
$$

This last condition reflects the fact that the time devoted to teaching is not available for goods production. We are now ready to define an equilibrium for our economy:

Definition 1 Given an initial distribution of human capital $F_{0}\left(h_{0}\right)$, an initial stock of physical capital $K_{0}$, and an initial population size $P_{0}$, an equilibrium consists of sequences of prices $\left\{w_{t}, R_{t}\right\}$, aggregate quantities $\left\{L_{t}, K_{t+1}, \bar{h}_{t}, P_{t+1}\right\}$, distributions $F_{t+1}\left(h_{t+1}\right)$, and decision rules $\left\{c_{t}, d_{t+1}, s_{t}, n_{t}, e_{t}, h_{t+1}\right\}$ such that: 
1. the households' decision rules $c_{t} d_{t+1}, s_{t}, n_{t}, e_{t}, h_{t+1}$ maximize utility subject to the constraints (1), (2), and (3);

2. the firm's choices $L_{t}$ and $K_{t}$ maximize profits;

3. the prices $w_{t}$ and $R_{t}$ are such that markets clear, i.e., (8) and (9) hold;

4. the distribution of human capital evolves according to (6);

5. aggregate variables $P_{t}$ and $\bar{h}_{t}$ are given by (4), (5) and (7).

\section{Theoretical Results}

We begin the analysis of the model by characterizing the quality-quantity tradeoff faced by individuals. We find that education increases and fertility decreases with income. The size of the differentials depends on the initial dispersion of human capital. To examine the long-run implications of the model, we characterize the balanced growth path. Finally, we examine the dynamics of individual human capital as a function of the parameters.

\subsection{The Tradeoff between the Quality and Quantity of Children}

The key variable for decisions in our economy is the human capital $h_{t}$ of a family relative to the average human capital $\bar{h}_{t}$ of the population. We denote the relative human capital of a household as:

$$
x_{t} \equiv \frac{h_{t}}{\bar{h}_{t}} .
$$

For a household that has enough human capital such that the condition $x_{t}>\frac{\theta}{\phi \eta}$ holds, there is an interior solution for the optimal education level, and the first-order 


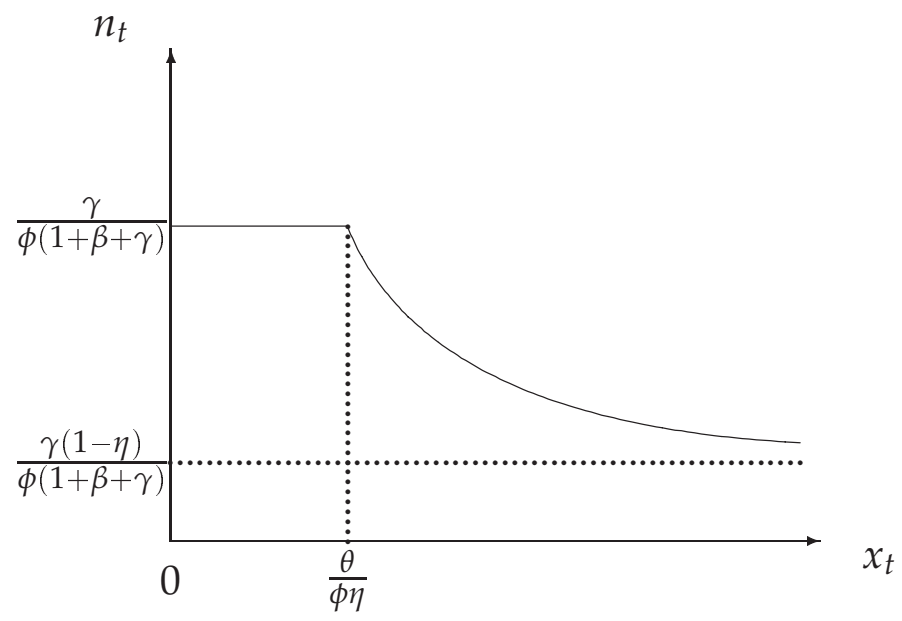

Figure 1: Fertility as a Function of Human Capital

conditions imply:

$$
\begin{aligned}
s_{t} & =\frac{\beta}{1+\beta+\gamma} w_{t} h_{t}, \\
e_{t} & =\frac{\eta \phi x_{t}-\theta}{1-\eta}, \\
n_{t} & =\frac{(1-\eta) \gamma x_{t}}{\left(\phi x_{t}-\theta\right)(1+\beta+\gamma)} .
\end{aligned}
$$

The second-order conditions for a maximum are satisfied. Note that:

$$
\frac{\partial e_{t}}{\partial x_{t}}>0 \text { and } \frac{\partial n_{t}}{\partial x_{t}}<0,
$$

which reflects the well-documented fact that skilled people invest relatively more in the quality of their children than in their quantity. The reason is that the cost of education is fixed, while the time cost of raising many children increases with income. The lowest possible fertility rate is given by:

$$
\lim _{x_{t} \rightarrow \infty} n_{t}=\frac{\gamma(1-\eta)}{\phi(1+\beta+\gamma)} .
$$

For poorer households endowed with sufficiently little human capital such that $x_{t} \leq$ 
$\frac{\theta}{\phi \eta}$ holds, the optimal choice for education $e_{t}$ is zero. The first-order conditions imply equation (10) and:

$$
\begin{aligned}
e_{t} & =0, \\
n_{t} & =\frac{\gamma}{\phi(1+\beta+\gamma)} .
\end{aligned}
$$

Once a household is at the corner solution and the choice for education is zero, fertility no longer increases as the human capital endowment falls.

Fertility as a function of human capital is plotted in Figure 1. The horizontal part of the relationship corresponds to the range of human capital which leads to a choice of zero for education $e_{t}$. Fertility depends negatively on human capital and moves within a finite interval. The upper bound on the fertility differential is given by:

$$
\frac{\lim _{x_{t} \rightarrow 0} n_{t}}{\lim _{x_{t} \rightarrow \infty} n_{t}}=\frac{1}{1-\eta} .
$$

This relationship will turn out to be helpful to interpret the role of the parameter $\eta$ and to calibrate its value.

The results derived so far reflect the main effects of inequality on growth that we are interested in. Assuming that all dynasties choose positive levels of education, equation (11) shows that education is a linear function of relative human capital. If the dispersion of human capital increases for a given average level of human capital, this linearity implies that the average education choice will still be the same. However, since the production function for human capital is concave in education, future average human capital will be lower if the distribution of human capital is less equal. This would be true even if fertility were constant across families with different human capital levels. The fact that fertility is actually higher for people with low human capital greatly amplifies the negative effect of inequality on human capital accumulation.

\subsection{The Balanced Growth Path}

To analyze the dynamic behavior of the economy, it is useful to rewrite the equilibrium conditions in terms of variables that are constant in the balanced growth path. 
The capital/labor ratio $k_{t}$, the growth rate of average human capital $g_{t}$, the population growth rate $N_{t}$, and the deflated level of average human capital $\hat{h}_{t}$ are defined by:

$$
k_{t} \equiv \frac{K_{t}}{L_{t}}, \quad g_{t} \equiv \frac{\bar{h}_{t+1}}{\bar{h}_{t}}, \quad N_{t} \equiv \frac{P_{t+1}}{P_{t}}, \quad \hat{h}_{t} \equiv \frac{\bar{h}_{t}}{(1+\rho)^{t}} .
$$

We also need to define the distribution of the relative human capital levels:

$$
G_{t}\left(x_{t}\right) \equiv F_{t}\left(x_{t} \bar{h}_{t}\right)
$$

Rewriting equations (4), (5), (6) and (7) in terms of the stationary variables leads to:

$$
\begin{aligned}
\hat{h}_{t+1} & =\frac{g_{t}}{1+\rho} \hat{h}_{t} \\
N_{t} & =\int_{0}^{\infty} n_{t} \mathrm{~d} G_{t}\left(x_{t}\right), \\
G_{t+1}(x) & =\frac{1}{N_{t}} \int_{0}^{\infty} n_{t} I\left(x_{t+1} \leq x\right) \mathrm{d} G_{t}\left(x_{t}\right), \\
1 & =\int_{0}^{\infty} x_{t} \mathrm{~d} G_{t}\left(x_{t}\right) .
\end{aligned}
$$

Prices follow from the competitive behavior of firms, which leads to equalization of marginal costs and productivities:

$$
\begin{gathered}
w_{t}=A(1-\alpha) k_{t}^{\alpha}, \\
R_{t}=A \alpha k_{t}^{\alpha-1} .
\end{gathered}
$$

Schooling and fertility decisions are given by (13) and (14) for $x_{t}<\theta /(\eta \phi)$ and by (11) and (12) otherwise. The number of children for an adult with relative human capital $x_{t}$ is thus given by:

$$
n_{t}=\min \left[\frac{(1-\eta) \gamma x_{t}}{\left(\phi x_{t}-\theta\right)(1+\beta+\gamma)}, \frac{\gamma}{\phi(1+\beta+\gamma)}\right]
$$

From equation (3), the children's human capital is given by:

$$
x_{t+1}=\frac{B x_{t}^{\tau}}{g_{t}}\left(\theta+\max \left[0, \frac{\eta \phi x_{t}-\theta}{1-\eta}\right]\right)^{\eta}\left(\hat{h}_{t}\right)^{\tau+\kappa-1} .
$$


From equation (9), labor input satisfies:

$$
\frac{L_{t}}{P_{t} \bar{h}_{t}}=\int_{0}^{\frac{\theta}{\eta \phi}} \frac{(1+\beta) x_{t}}{1+\beta+\gamma} \mathrm{d} G_{t}\left(x_{t}\right)+\int_{\frac{\theta}{\eta \phi}}^{\infty}\left(1-\gamma \frac{\phi(1-\eta)+\left(\eta \phi x_{t}-\theta\right)}{\left(\phi x_{t}-\theta\right)(1+\beta+\gamma)}\right) x_{t} \mathrm{~d} G_{t}\left(x_{t}\right) .
$$

which leads to:

$$
\frac{L_{t}}{P_{t} \bar{h}_{t}}=\frac{1+\beta}{1+\beta+\gamma}
$$

Using (8), (10), (19) and (22), the capital stock evolves according to the following law of motion:

$$
k_{t+1}=\frac{\beta}{1+\beta} \frac{1}{g_{t} N_{t}} A(1-\alpha) k_{t}^{\alpha} .
$$

Given initial conditions $k_{0}, \hat{h}_{0}$ and $G_{0}\left(x_{0}\right)$, an equilibrium can be characterized by sequences $\left\{\hat{h}_{t+1}, g_{t}, n_{t}, G_{t+1}(x), N_{t}, x_{t}, k_{t+1}\right\}$ such that (15), (16), (17), (18), (20), (21), and (23) hold at all dates.

This dynamic system is block recursive. Given the initial conditions, we can first use (20) to solve for $n_{t}$. Then equations (18) and (21) determine $x_{t+1}$ and $g_{t}$. Leading (18) by one period and replacing $x_{t+1}$ by its value from (21) yields an expression where $g_{t}$ can be computed as a function of past variables, $x_{t}$ and $\hat{h}_{t}$. The new distribution of relative human capital is given by equation (17). The variable $\hat{h}_{t+1}$ is obtained from (15), the aggregate population growth rate $N_{t}$ from (16), and the future capital-labor ratio $k_{t+1}$ from (23). This procedure can be used to compute an equilibrium for any initial conditions. The future distribution of human capital is always well defined and non-negative. Given any initial conditions, an equilibrium therefore exists and is unique.

Concerning the long-run behavior of the economy, it follows from these equations that there is a balanced growth path in which everyone has the same human capital:

Proposition 1 If $\eta \phi>\theta$, there is a balanced growth path characterized by $d G(1)=1$ (i.e. the limiting distribution is degenerate). The growth factor of output and human capital is:

$$
\begin{array}{cl}
g^{\star}=B\left(\frac{\eta(\phi-\theta)}{1-\eta}\right)^{\eta} & \text { if } \kappa=1-\tau \text { (endogenous growth), } \\
1+\rho & \text { otherwise (exogenous growth), }
\end{array}
$$


and the growth factor of population is:

$$
N^{\star}=\frac{(1-\eta) \gamma}{(\phi-\theta)(1+\beta+\gamma)}
$$

Proof: See Appendix A.

Q.E.D.

Along this balanced growth path, there is no longer any inequality among households. This holds because we have assumed that households differ only in their initial level of human capital. If we had introduced ability shocks on top of an unequal initial distribution of human capital, inequality would persist along the balanced growth path. We abstract from idiosyncratic shocks in the presentation of the model, since they do not play a role in the channel from inequality to growth that we are interested in. However, shocks can influence the long-run dynamic behavior of the model. Therefore we introduce ability shocks as an extension in Section 4.3 below.

We will assume $\eta \phi>\theta$ from here on. We now consider the dynamics of the human capital of an individual dynasty (of mass zero) around an aggregate balanced growth path. This will be useful to understand the role of the parameter $\tau$ for the dynamic properties of the model.

\subsection{The Dynamics of Individual Human Capital}

To study the dynamics of individual human capital, we assume that the economy is on a balanced growth path, so that the growth rate of average human capital is constant over time: $g_{t}=g^{\star}$. We focus on the effect of the parameter $\tau$ on the dynamics of individual human capital. We consider the function $x_{t+1}-x_{t}=\Psi\left(x_{t} ; \tau\right)$ (the change in relative human capital $x_{t}$ as a function of $x_{t}$ and $\tau$ ), which is given by:

$$
\Psi(x ; \tau)=\left(\frac{1-\eta}{\eta(\phi-\theta)}\right)^{\eta} x^{\tau}\left(\theta+\max \left[0, \frac{\eta \phi x-\theta}{1-\eta}\right]\right)^{\eta}-x .
$$

As shown in Appendix B, $\Psi\left(x_{t} ; \tau\right)$ is obtained from equation (21) after replacing $g^{\star}$ and $\hat{h}$ by their steady-state values. Note that in the endogenous and exogenous growth cases the function $\Psi(x ; \tau)$ turns out to be the same. 


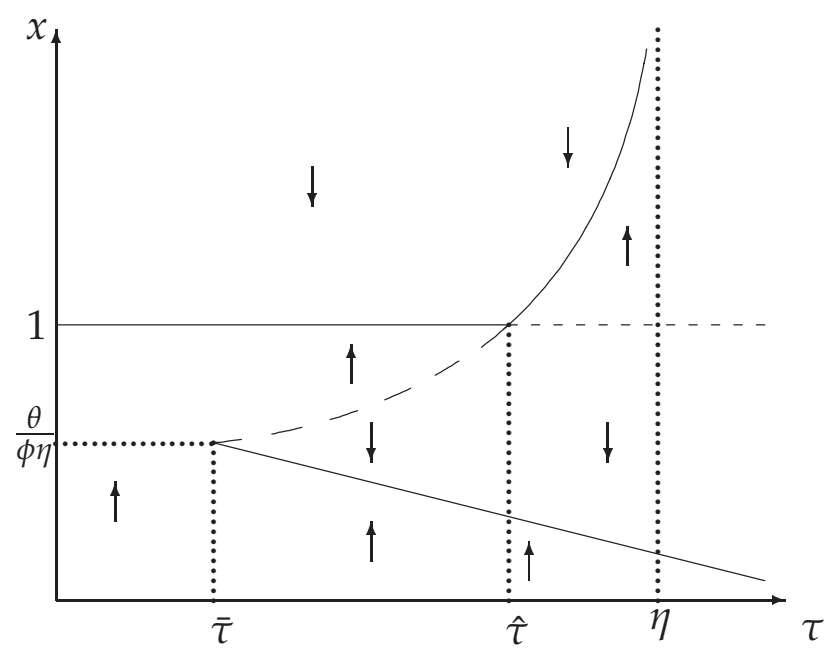

Figure 2: Steady States as a Function of $\tau$

A detailed study of $\Psi\left(x_{t} ; \tau\right)$ is performed in Appendix B. A complete characterization of the dynamics of $x_{t}$ as a function of the parameter $\tau$ is presented in the bifurcation diagram in Figure 2. The steady states $x$ are represented on the vertical axis as a function of $\tau$. For small $\tau$ there is only one steady state, $x=1$, which is globally stable. Once $\tau$ reaches a threshold $\bar{\tau}$ (given in the appendix) two additional steady states appear. The lower one is stable and the second is unstable. This threshold arises at the point where the cutoff value for an interior solution is a steady state of the individual dynamics. Moreover:

Proposition 2 At the point:

$$
\hat{\tau}=1-\frac{\eta \phi}{\phi-\theta}
$$

the dynamics of individual capital described by $x_{t+1}-x_{t}=\Psi\left(x_{t} ; \tau\right)$ undergo a transcritical bifurcation. There are two steady-state equilibria, 1 and $\bar{x}$, near $(1, \hat{\tau})$ for each value of $\tau$ smaller or larger than $\hat{\tau}$. The equilibrium 1 (resp. $\bar{x}$ ) is stable (resp. unstable) for $\tau<\hat{\tau}$ and unstable (resp. stable) for $\tau>\hat{\tau}$.

Proof: We check the five conditions that define such a bifurcation in Wiggins (1990), p. 365:

$$
\Psi(1, \hat{\tau})=0, \quad \Psi_{x}^{\prime}(1, \hat{\tau})=0, \quad \Psi_{\tau}^{\prime}(1, \hat{\tau})=0,
$$




$$
\Psi_{x x}^{\prime \prime}(1, \hat{\tau})=-\frac{\eta \theta \phi}{(\phi-\theta)^{2}} \neq 0, \quad \Psi_{x \tau}^{\prime \prime}(1, \hat{\tau})=1 \neq 0
$$

Q.E.D.

This bifurcation occurs when an unstable and a stable fixed point collide and exchange stability. That is, the unstable fixed point becomes stable and vice versa. ${ }^{1}$ When $\tau$ increases beyond $\hat{\tau}$, the high steady state increases and then vanishes once $\tau>\eta$. Thus, for individual dynamics to be stable, it is essential that $\tau$ be not too high. In the next section, we calibrate the model parameters to data and find that the stable region for $\tau$ is the empirically relevant case. The analysis of the dynamics of $x_{t}$ at given aggregate conditions is helpful to understand the numerical simulations carried out in the next section.

\section{Computational Experiments}

The theoretical results in the previous section highlight two channels through which inequality affects growth in this model. First, inequality in human capital leads to inequality in education, and since the production function for human capital is concave, inequality in education lowers future average human capital. Second, people with lower human capital not only choose less education for their children, but also a higher number of children. This differential-fertility effect increases the weight in the population on families with little education, which also lowers future human capital. The question arises which effect is more important, and how large the effects are quantitatively. To answer this question, we calibrate our model and provide numerical simulations of the evolution of fertility, inequality, human capital, and income. The main findings are that the effects of inequality on human capital accumulation and growth are sizable, and that the differential-fertility effect is crucial for generating this result.

We also use the calibrated model to analyze the dynamic implications of our theory. Here, a key finding is that for reasonable parameterizations, the model generates a "hump-shape" in inequality and population growth which first increase and then fall

\footnotetext{
${ }^{1}$ Note that beyond the bifurcation point the number of fixed points does not change, whereas in a saddle-node bifurcation two fixed points either appear or disappear.
} 
during development. This feature enables the model to reproduce broad features of the evolution of inequality, economic growth, and population growth in industrialized countries during development. This outcome lends additional support to the relationship between inequality, fertility, and growth postulated model.

\subsection{Calibration}

We choose the parameters of the model such that the balanced growth path resembles empirical features of the U.S. economy and population. The production function for human capital is calibrated to match observed fertility differentials, as well as empirical estimates of the effects of education on future earnings.

The model is calibrated under the assumption that one period (or generation) has a length of thirty years. The parameter $\alpha$ is the capital share in the consumption good sector and is set to $1 / 3$ to match the empirical counterpart. The productivity level $A$ is a scale parameter and is set to $A=1$. The discount factor $\beta$ mainly affects the ratio of human capital to physical capital in the balanced growth path. Since this ratio depends on the choice of units, it does not provide a convenient basis for calibrating $\beta$. Given that $\beta$ does not influence qualitative features of the model that we are interested in, we choose a value that is standard in the real-business-cycle literature, $\beta=0.99^{120}$ (i.e., 0.99 per quarter). The implied interest rate per year is $4.7 \%$. The productivity growth rate $\rho$ governs output growth in the balanced growth path, and is set to $1.02^{30}$ or $2 \%$ per year, which approximates the average growth rate in the U.S. With exogenous growth (i.e., $\kappa<1-\tau$ ) as in our calibration, the overall productivity $B$ in the production function for human capital is a scale parameter and is set to $B=1$.

The weight $\gamma$ of children in the utility function governs the growth rate of population in the balanced growth path. In the U.S. as in other industrialized countries, fertility rates are close to the reproduction level. Accordingly, we choose $\gamma$ such that the growth rate of population in the balanced growth path is zero. This is achieved by choosing $\gamma=0.271 .^{2}$ The time-cost parameter $\phi$ for having a child determines the overall opportunity cost of children. Evidence in Haveman and Wolfe (1995) and

\footnotetext{
${ }^{2}$ Since convergence to the balanced growth path is slow, the model still allows for substantial population growth for long time periods.
} 
Knowles (1999) suggests that the opportunity cost of a child is equivalent to about $15 \%$ of the parents' time endowment. This cost only accrues as long as the child is living with the parents. If we assume that children live with parents for 15 years and that the adult period lasts for 30 years, the overall time cost should be $50 \%$ of the time cost per year with the child present. Accordingly, we choose $\phi=0.075$. The parameter $\phi$ also sets an upper limit on the number of children a person can have. With our choice, a person spending all time on raising children would have a little above thirteen children. A family of two could have a little under 27 children. ${ }^{3}$

The parameter $\eta$ influences the elasticity of human capital with respect to education, as well as the maximum fertility differential in the economy. Specifically, the maximum differential written as a ratio is given by $1 /(1-\eta)$. In the data set that we use below, the highest fertility ratio between women at the lowest and the highest education levels is 2.74 (Brazil). This differential is achieved by choosing $\eta=0.635$. Our choice of $\eta$ guarantees that realized fertility differentials in the model never exceed the maximum differential observed in the data, which ensures that the role of the differential-fertility channel is not inflated. At the same time, for evaluating the differential-fertility channel it is also important that the elasticity of future human capital with respect to education is calibrated realistically. In the model, this elasticity is determined jointly by $\eta$ and $\theta$. Since $\theta$ enters the education choice of parents, it determines aggregate expenditures on education. We choose $\theta$ such that in the balanced growth path total education expenditure as a fraction of GDP matches the corresponding value in U.S. data, which is $7.3 \% .^{4}$ The implied parameter value is $\theta=0.0119$. Our combined choices for $\eta$ and $\theta$ imply an elasticity of human capital with respect to education of 0.6 in the balanced growth path. This number is within the range of estimates of the elasticity of earnings with respect to schooling. Specifically, estimates of the return to an additional year of schooling range from $7.5 \%$ in Angrist and Krueger (1991) to 12 to 16\% in the study of twins by Ashenfelter and Krueger (1994). The surveys by Psacharopoulos (1994) and Krueger and Lindahl (2001) report estimates of the return to schooling in developed countries of 8-10\%, with higher estimates for developing countries and low levels of schooling. Assum-

\footnotetext{
${ }^{3}$ If we also modeled a goods cost of having children, the upper bound would be lower, and close to the maximum human fertility levels observed so far.

${ }^{4}$ This figure (Digest of Education Statistics, 1998, US Department of Education) does not include on-the-job training, since it is not part of the parental investment in children.
} 
ing that an additional year of schooling raises education expenditure by $20 \%$, these returns translate into an earnings elasticity of schooling between 0.4 and 0.8 . The elasticity implied by our parameter choices is exactly in the middle of this range.

The remaining parameters $\kappa$ and $\tau$ do not influence individual decisions, but still have an effect on growth rates. The elasticity $\kappa$ of future human capital with respect to average human capital $\bar{h}$ can be calibrated to evidence on the effects of the quality of schooling. We interpret the education choice $e_{t}$ as the quantity of schooling (corresponding to years of schooling in the data) while $\bar{h}$ measures the quality of schooling, since it is the average human capital of teachers. Compared to the quantity of schooling, the quality of schooling (such as spending per pupil at a given level of education) has been shown to have smaller effects on earnings with an elasticity of around 0.1, see Card and Krueger (1996) and Krueger and Lindahl (2001). In line with evidence on the effect of the quality of education, we set $\kappa=0.1$. Alternatively, $\kappa$ could also be interpreted as a measure of human capital externalities. Existing evidence (see Acemoglu and Angrist 2000 and Krueger and Lindahl 2001) suggests that these externalities are small as well, i.e., the social return to human capital accumulation is only slightly larger than the private return, confirming our low choice of $\kappa$. Our results are robust with respect to the choice of this elasticity in the sense that $\kappa$ matters only for the determination of the growth rate of average human capital. Individual decisions and the evolution of inequality, fertility, and differential fertility are independent of $\kappa$.

The parameter $\tau$ determines the direct effect of parental human capital (or, equivalently, income) on the children's human capital. Thus, $\tau$ captures the intergenerational transmission of ability, as well as human capital formation within the family that does not work through formal schooling. Empirical studies detect such effects, but they are relatively small. Rosenzweig and Wolpin (1994) find that an additional year of the mother's education at the high school level (roughly a 10\% increase in education) raises a child's test scores by $2.4 \%$. Leibowitz (1974) finds that even after controlling for schooling and education of the parents, parental income has a significant effect on a child's earnings. A 10\% increase in parental income increases a child's future earnings by up to $0.85 \%$. Given that the long-run dynamics of the model are sensitive to the choice of $\tau$, we choose a moderate degree of intergenerational transmission of human capital ( $\tau=0.2)$ as the baseline case, and provide a sensitivity 
analysis with respect to alternative choices for $\tau$. For individual dynamics to be stable, $\tau$ must not exceed the upper bound $\hat{\tau}$ from Proposition 2. Given our choices for the other parameters, the upper limit for $\tau$ is 0.246 , which is well above the calibrated value.

In addition to choosing parameters, we also need to set the initial conditions for the simulations. The overall size of the population is a scale parameter which does not affect the results, and is therefore set to one. Likewise, the distribution of physical capital does not matter, since capital is owned by old people who have nothing left to decide. We therefore only specify the aggregate value. The initial distribution of human capital follows a log-normal distribution $F\left(\mu, \sigma^{2}\right)$, where $\mu$ and $\sigma^{2}$ are the mean and variance of the underlying normal distribution. The parameter $\mu$ is set such that $\hat{h}_{t}$ is at its balanced-growth level. We provide simulations for different variances of the distribution in order to examine the effects of inequality. The initial level of physical capital $K_{0}$ is chosen such that the ratio of physical to human capital is equal to its value in the balanced growth path. ${ }^{5}$

\subsection{Initial Inequality, Fertility, and Growth}

As a first computational experiment, we examine the effect of initial inequality on growth over the first period. Since a period is in fact a generation, the growth rate should be interpreted as a thirty-year average. The main findings are that inequality has a sizable effect on growth, and that most of this effect is accounted for by the endogenous fertility differential.

Table 1 presents the initial annualized growth rates of human capital $g_{0}$ and population $N_{0}$, initial inequality $I_{0}$, and the initial fertility differential $D_{0}$ for different variances of the distribution of human capital. Inequality is measured by the Gini coefficient $I_{0}$ computed on the earnings of the working population. Differential fertility is the difference between the average fertility of the top quintile and the bottom quintile; this quantity is then multiplied by two to yield a number per woman. To evaluate the role of differential fertility in our model, we also computed results under the assumption of constant, exogenous fertility.

\footnotetext{
${ }^{5}$ The effect of inequality on growth is independent of $\mu$ and $K_{0} ; \mu$ and $K_{0}$ only affect average growth rates.
} 


\begin{tabular}{|c|c|c|c|c|c|c|c|c|}
\hline \multirow[b]{2}{*}{$\sigma^{2}$} & \multicolumn{4}{|c|}{ Endogenous Fertility } & \multicolumn{4}{|c|}{ Exogenous Fertility } \\
\hline & $g_{0}$ & $N_{0}$ & $I_{0}$ & $D_{0}$ & $g_{0}$ & $N_{0}$ & $I_{0}$ & $D_{0}$ \\
\hline 0.10 & $2.00 \%$ & $0.00 \%$ & 0.056 & 0.09 & $2.00 \%$ & $0 \%$ & 0.056 & 0 \\
\hline 0.75 & $1.26 \%$ & $0.66 \%$ & 0.404 & 1.95 & $1.87 \%$ & $0 \%$ & 0.400 & 0 \\
\hline 1.00 & $0.80 \%$ & $1.08 \%$ & 0.520 & 2.76 & $1.78 \%$ & $0 \%$ & 0.513 & 0 \\
\hline 1.50 & $0.01 \%$ & $1.71 \%$ & 0.707 & 2.77 & $1.53 \%$ & $0 \%$ & 0.700 & 0 \\
\hline
\end{tabular}

Table 1: Initial Growth with Endogenous and Exogenous Fertility

The results in Table 1 show that inequality lowers growth both with and without endogenous fertility, but the effects are much larger when fertility is endogenous. When the variance of the distribution of human capital is low $\left(\sigma^{2}=0.10\right)$, the difference between endogenous and exogenous fertility is small, and the growth rates are close to their values on the balanced growth path. When we increase the initial variance to $\sigma^{2}=0.75$, substantial fertility differentials within the population begin to arise, and the annual growth rate of human capital drops $0.74 \%$ below the steady state. With constant exogenous fertility, the drop in the growth rate is six times smaller. Further increases in the initial variance eventually lead to a negative growth rate (for $\sigma^{2}>1.5$ ) with endogenous fertility, while growth stays positive with exogenous fertility.

The results are robust with respect to the choice of $\tau$. For example, with $\sigma^{2}=0.75$, initial growth with endogenous fertility is $1.22 \%$ for $\tau=0.05$, and $1.32 \%$ for $\tau=0.3$. With exogenous fertility, it is $1.80 \%$ for $\tau=0.05$, and $1.94 \%$ for $\tau=0.3$. We also carried out the same computations with a uniform instead of a log-normal distribution of initial human capital. We still found that growth declines much faster with inequality when fertility is endogenous. For example, when the Gini index goes from 0 to 0.33 , growth drops by $0.7 \%$ with endogenous fertility and by $0.1 \%$ with exogenous fertility.

The initial dispersion of human capital also influences the overall growth rate of population. When the variance of human capital rises, fertility of low-skilled households increases, while high-skilled households decide to have fewer children. Because of the shape of the fertility function (see Figure 1), the first effect dominates and aggregate fertility rises. This is in line with empirical studies that report a high positive correlation between aggregate fertility rates and Gini coefficients (see Barro 2000). 


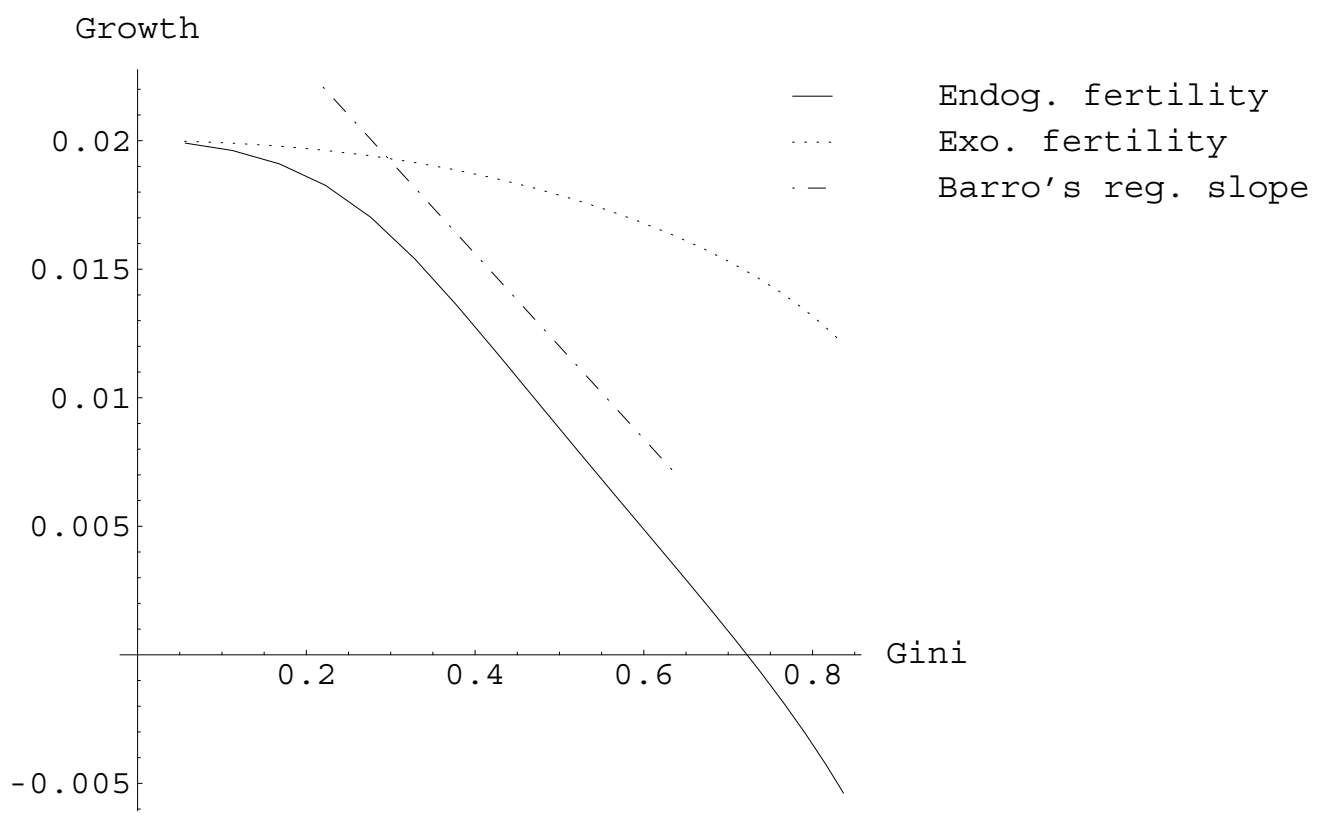

Figure 3: The Relationship of Inequality and Growth

Figure 3 depicts the growth rate of human capital as a function of the Gini coefficient. The slope is much steeper with endogenous fertility than with exogenous fertility. In the data, income Ginis for a country vary roughly in the range 0.2 to 0.65 . In the model, raising the initial Gini from 0.2 to 0.65 lowers the growth rate by only about $0.3 \%$ with exogenous fertility, but by $1.4 \%$ with endogenous fertility. In a quantitative sense, fertility differentials within the population are essential for generating the relationship between inequality and growth.

We have also represented the slope of the regression of economic growth on income Ginis run by Barro (2000) when the fertility rate variable is omitted. In this regression, the Gini coefficient captures the intrinsic effect of inequality as well as the one going through fertility. Since actual Gini coefficients lie in the interval [.21,.64], the regression line has been restricted to this interval. Our computational experiment is consistent with the Barro (2000) finding: "A reduction of the Gini coefficient by 
0.1 would be estimated to raise the growth rate on impact by 0.4 percent per year."6 Perotti (1996) reports effects of similar magnitude. Our calibrated model is therefore able to account for most of the empirical relationship between inequality and growth. Since the empirical estimates carry sizable standard errors, the finding does not rule out that other channels could also play a role, but clearly the differential-fertility effect appears to be important.

\subsection{The Dynamics of Inequality, Differential Fertility, and Growth}

We now turn to the dynamic implications of our model. So far, we have only analyzed the effects of inequality on growth during the initial period. Since in our dynastic model a period has a length of 30 years, even the initial growth effect extends over a long horizon, and consequently the dynamics of the model are to be interpreted as changes which occur over a horizon of a century or more. We therefore evaluate the dynamic behavior of the model relative to the evolution of income, fertility, and inequality in industrializing countries in the last 200 years. A central feature of the data for this period is that the behavior of population growth and inequality is non-monotone. As a benchmark case, consider England, the first country to industrialize. Fertility rates increased until about 1830 and started to decline rapidly only after 1870 (Chesnais 1992). Income inequality followed a similar pattern, with increasing inequality until about 1870 and a rapid decline afterwards (Williamson 1985). The growth rate of income per capita, in contrast, does not display a humpshape. Growth rates were essentially zero before the industrial revolution and then increased slowly throughout the 19th century (Maddison 2001). Similar patterns can be observed for Western Europe as a whole and, starting a little later, in the United States.

To evaluate how our model performs relative to these facts, we simulate the model

\footnotetext{
${ }^{6}$ The comparison to Barro's result is complicated by the fact that Barro conditions his estimates on initial GDP, whereas in our simulations GDP is partly a function of the initial income distribution. Thus, in principle, the simulations pick up the additional effect of changing initial GDP. In practice, however, this effect turns out to be negligible. Initial GDP varies only to the extent that child-rearing time is not included in GDP, and the resulting differences in GDP across inequality levels are small (up to $0.3 \%$ ). We computed results with an additional adjustment in average human capital that holds GDP per worker constant across inequality levels. The results are virtually indistinguishable from the ones reported in Figure 3.
} 
with the baseline calibration over a horizon of eight periods, corresponding to 240 years. The main finding is that for plausible parameters, the model can generate a hump-shape in inequality and the population growth rate that looks very similar to the data. This is a surprising finding, since unlike most existing theories the model generates the pattern without requiring any exogenous change to the economic environment. We also investigate the behavior of the model if idiosyncratic shocks are added to the production function for human capital, since for long-run analysis the assumption that the only source of inequality is the initial dispersion in human capital is less attractive. We find that adding shocks slows growth, but leaves the qualitative behavior of the model intact. Thus our model turns out to be successful at accounting for both the cross-sectional relationship between inequality and growth, and the dynamic interaction between inequality, fertility, and growth over long time horizons.

Figure 4 shows the evolution of the growth rate of human capital, the population growth rate, inequality, and differential fertility for two different values of $\tau$. Growth rates are annualized. The initial distribution of human capital is assumed log-normal with $\sigma^{2}=1$, corresponding to an initial Gini coefficient of 0.5 . With a low $\tau$ of 0.05 , fertility, inequality, and differential fertility converge monotonically to their steadystate values. Initially, inequality reduces growth below its balanced-growth value for the reasons explained above, but subsequently the growth rate increases. Low initial growth implies that the capital stock increases more slowly than in the balanced growth path. Since productivity growth is exogenous, the effective capital stock falls, and the usual transitional dynamics in exogenous-growth models result in higher subsequent growth. If $\tau$ is raised to 0.2 , the model generates the hump-shape patterns that characterize the data. Fertility and inequality first rise and then decrease, and the growth rate remains below its balanced-growth value for several periods as long as inequality remains high. A moderate degree of intergenerational persistence in human capital is thus essential for matching the long-run evolution of inequality and fertility to data.

The non-monotone behavior of inequality and fertility is related to the corner solution for education. A fraction of the people in the first period decides not to invest in education. Since this group has the highest fertility rates, their children make up an even larger fraction of the population in the next period. If there is a sufficient degree of intergenerational persistence, these children will be at the corner solution for edu- 

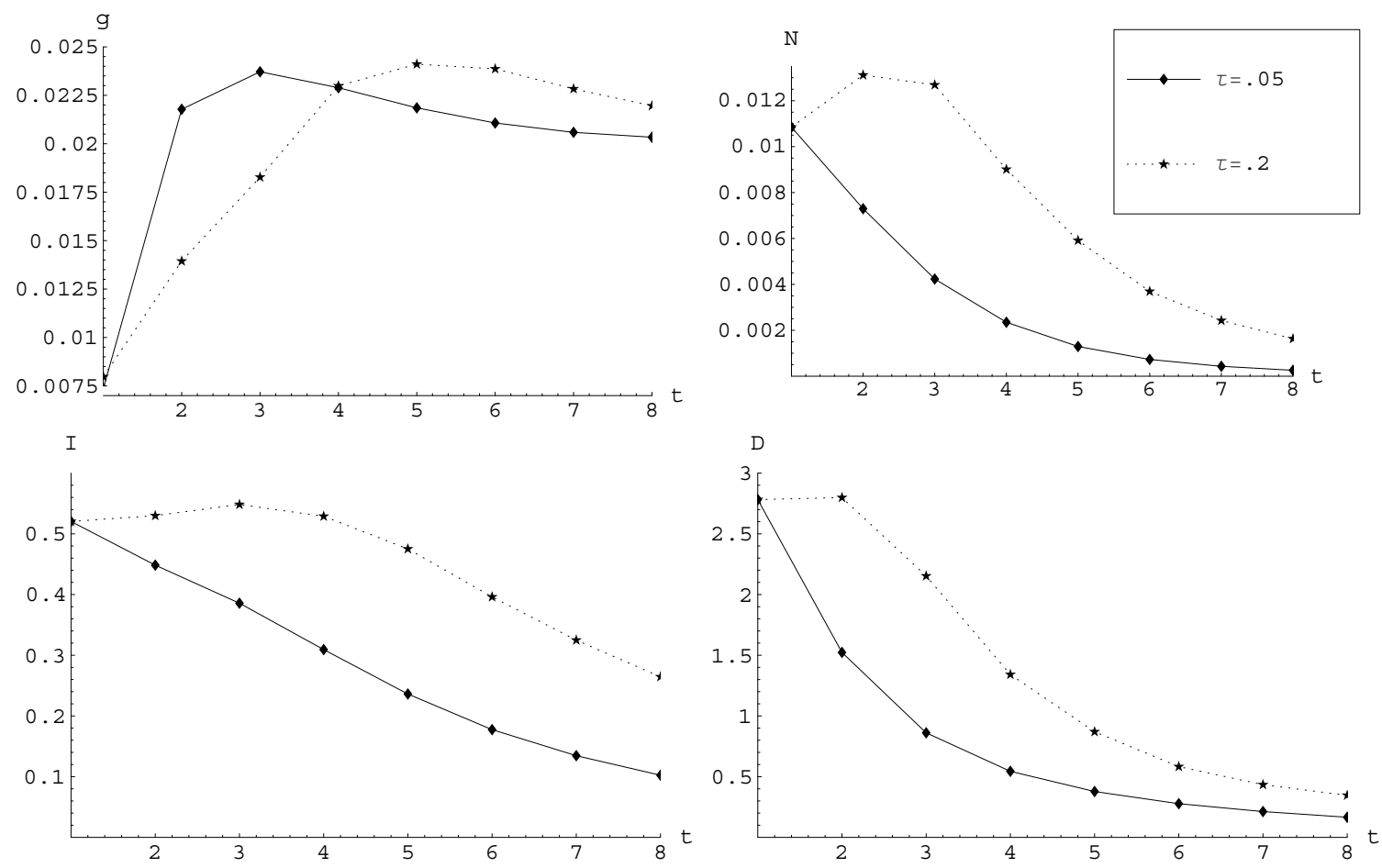

Figure 4: Growth, Fertility, Inequality, and Differential Fertility for Different $\tau$

cation as well. This leads to an increase in population growth in the first periods and slow growth of human capital, since investment in education is low. Because of exogenous technological change and human capital externalities, however, after a few periods even the dynasties that initially did not invest in education find it optimal to start educating their children. From this point on, inequality and population growth fall.

This non-monotone behavior only occurs if the initial distribution of human capital is such that some people choose not to invest in education. If everyone is above the threshold initially, convergence to the steady state is monotone even for $\tau=0.2$. For parameters that lead to an initial rise in fertility and inequality, the time paths for inequality, growth, and fertility look surprisingly similar to the patterns of development in Western Europe between 1800 and 2000 described by Galor and Weil (2000) and others. For example, let us assume that $t=1$ in the graphs corresponds to the period 1760-90 in England. Then population growth peaks around 1790-1820, and inequality peaks 30 years later. The timing of the subsequent fall is close to what is 
observed in the data. For the hump to occur, however, $\tau$ cannot be too small, i.e., we need some degree of intergenerational persistence in human capital and earnings. ${ }^{7}$

The main disparity between the model and the data is that in the data growth rates were slowly increasing throughout the nineteenth century, whereas the model produces a hump-shape with first rapidly increasing and then falling growth rates. This behavior of the model is generated by transitional dynamics due to the exogenousgrowth assumption. We therefore also explore how the model performs if we increase the human capital externality from $\kappa=0.1$ to $\kappa=1-\tau=0.8$ to allow for endogenous growth. As stressed above, individual decisions and the evolution of inequality, fertility, and differential fertility are independent of the assumption on $\kappa$. However, the dynamic pattern of the growth rate can be affected. ${ }^{8}$ Figure 5 compares growth rates under the two different regimes with U.K. data from Maddison (2001). While growth with $\kappa=0.1$ increases quickly and soon exceeds its balanced-growth value, with $\kappa=1-\tau$ growth converges slowly and monotonically to its long-run level. The pattern under the endogenous growth assumption is closer to the observed pattern in England, where the average growth rate of $2 \%$ was reached only towards the beginning of the twentieth century. Notice, however, that to generate endogenous growth we have to assume a much higher degree of externalities than suggested by empirical estimates in recent data. The result therefore indicates that either externalities played a bigger role in the past, or that another endogenous growth mechanism was at work which generated the slowly increasing growth rates.

So far, we have assumed that the only source of inequality is the initial dispersion in human capital. As a consequence, inequality is transitory in the model and disappears in the balanced growth path. While this abstraction is of no consequence for the initial growth effects, for long-run dynamics idiosyncratic shocks would be expected

\footnotetext{
${ }^{7} \mathrm{~A}$ unique equilibrium exists even if we increase $\tau$ above the bifurcation value of $\hat{\tau}=.246$, where we enter the region of the parameter space in which the dynamics of individual human capital are no longer stable. The returns to parental human capital in the education function are not sufficiently decreasing to compensate the centrifugal force of the quality-quantity tradeoff. Computations of the distribution of human capital after a large number of periods indicate that an ever decreasing share of the population accumulates an ever increasing share of human capital. The mass of people with above-average human capital tends to zero, but the fraction of human capital accounted for by them tends to one.

${ }^{8}$ To calibrate the endogenous growth version of the model, we keep $\tau$ at 0.2 and set $\kappa=0.8$. The overall productivity $B$ in the production function for human capital now governs the growth rate of output per capita. We pick $B=0.367$ which ensures a long term growth rate of $2 \%$ per year.
} 


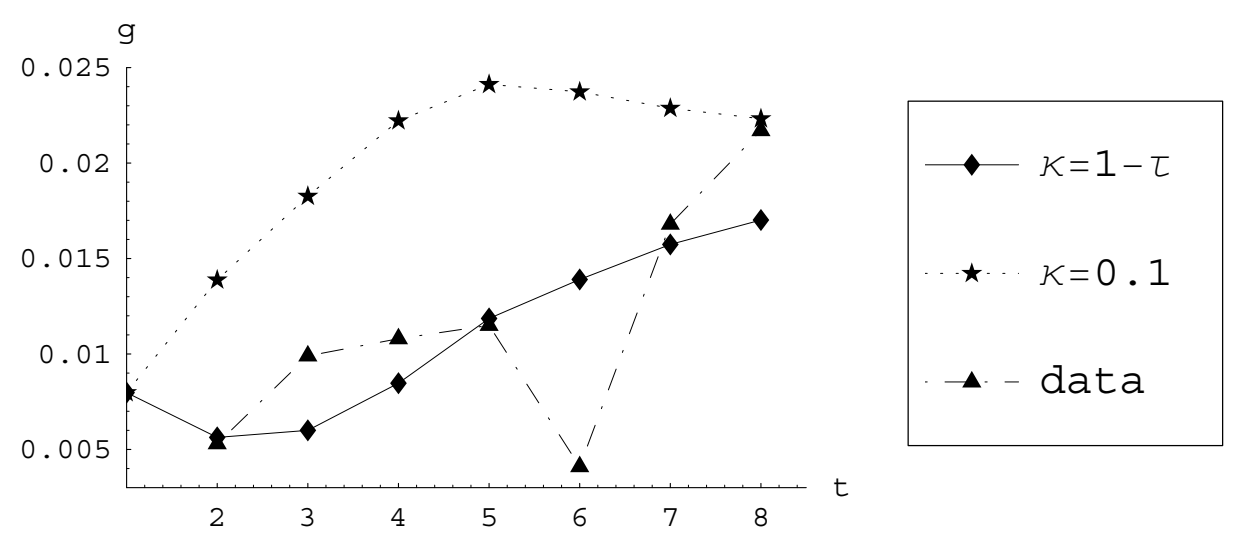

Figure 5: Exogenous versus Endogenous Growth

to be more important. To check the robustness of our results, we therefore extended the model by introducing idiosyncratic ability shocks in the production function for human capital. With ability shocks, inequality persists even in the long run.

The main outcome of our simulations with ability shocks is that inequality decreases more slowly and growth is reduced, which was to be expected, but that otherwise the qualitative features of the transition remain intact. The quantitative impact of ability shocks is rather small as well, provided that the shocks are calibrated to reproduce current levels of earnings inequality in the U.S. ${ }^{9}$ Moreover, as can be seen in Figure 6, the difference materializes only after several periods, since the ability shocks have little additional impact as long as the distribution of human capital is widely dispersed.

In summary, we find that our relatively simple model is surprisingly successful at reproducing key features of the long-run evolution of inequality, fertility, and growth. Under a moderate degree of intergenerational persistence in human capital (which could be generated by persistence in innate ability), the model generates a humpshape in inequality and fertility. In order to account for slowly increasing growth rates of income per capita, it is helpful to introduce an endogenous growth mechanism. While in our model endogenous growth is generated by human capital externalities, we conjecture that similar results could be obtained with other sources of endogenous growth.

\footnotetext{
${ }^{9}$ The ability shock is multiplicative and is drawn from a uniform distribution over $[0.9,1.1]$, which generates a long-term Gini coefficient of .35. We assume that the ability shock is uncorrelated with parental human capital, since the parameter $\tau$ already captures intergenerational transmission of skills.
} 

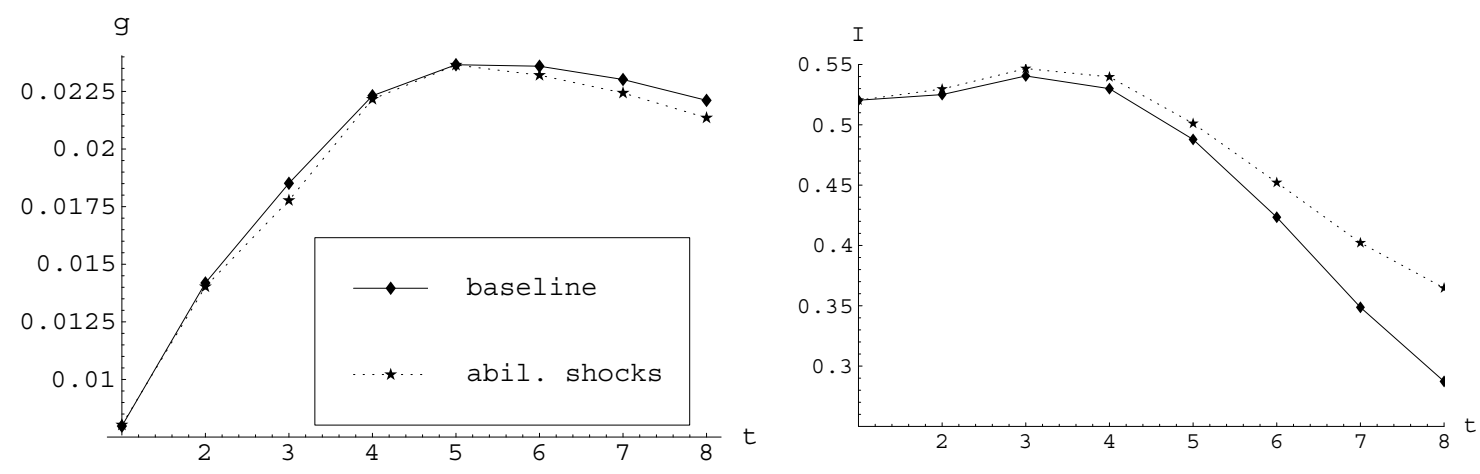

Figure 6: Growth and Inequality with and without Ability Shocks

Our results complement existing theories of long-run growth. Relative to the literature, the main novelty is that we link the evolution of growth and population to the income distribution. In contrast, the models developed by Hansen and Prescott (1999), Galor and Weil (2000), and Boucekkine, de la Croix, and Licandro (2002) abstract from distributional issues. ${ }^{10}$ We find that allowing for inequality in human capital combined with endogenous fertility and education choice generates realistic predictions for inequality, fertility, and growth in a simple and natural way. Galor and Weil (2000) generate a hump in fertility by introducing a subsistence level of consumption, but the evolution of the income distribution is not explained. In Hansen and Prescott (1999) fertility is exogenous, so neither the hump in fertility nor in inequality are accounted for. A limitation of our approach is that we take the initial conditions at the start of the industrial revolution as given. For a full account of the evolution of the economy from pre-industrial stagnation to modern growth we would have to add an element to the model that generates the initial stagnation phase. We suspect that this could be done along the lines of Galor and Weil (2000) or Hansen and Prescott (1999), but the extension is beyond the scope of the current paper.

A main implication of our dynamic analysis for the inequality-growth relationship is that the relationship can be modified by transitional dynamics. Since inequality first increases and then decreases during the transition, inequality does not map one-toone into growth rates. In the empirical analysis, it is therefore important to control

\footnotetext{
${ }^{10}$ Doepke (2001) has a model of the industrial revolution and the demographic transition which does allow for inequality. However, since there are only two types of agents, the income distribution has just two points. A hump in inequality arises only if there are exogenous policy changes.
} 
for transitional dynamics to isolate the role of the differential-fertility channel.

\section{Empirical Evidence}

Can the relationships between inequality, differential fertility, and growth postulated by our model be supported by empirical evidence? The first part of our hypothesis, that income inequality leads to high fertility differentials, has been analyzed by Kremer and Chen (2000). In line with our conjecture, they find that Gini coefficients have a significant and sizable positive correlation with fertility differentials. In this section we examine the second part of our hypothesis, the link from fertility differentials to growth. Our approach is to introduce a differential fertility variable into a standard growth regression. The analysis is designed to be comparable to recent empirical studies of inequality and growth. As predicted by our model, we find that differential fertility has a negative effect on growth. Moreover, when the differential fertility variable is present, the Gini variable is no longer significant in the regression.

\subsection{Data}

Our sample contains 68 countries for which data on fertility differentials is available. The dependent variable (GR) in all regressions is the average annual growth rate of GDP per capita over the periods 1960 to 1976 or 1976 to 1992 (the period depends on the availability of fertility data). The GDP data is from the Penn World Tables, and growth rates are continuously compounded and expressed as percentages. ${ }^{11}$ Since we are interested in long-run growth, we chose the longest sub-sample periods available in the Penn World Tables.

Following Kremer and Chen (2000), for fertility differentials we rely on information from the World Fertility Survey and the Demographic and Health Surveys on total fertility rates by women's educational attainment (see Jones 1982, United Nations 1987, Mboup and Saha 1998, and United Nations 1995). For countries that participated in the World Fertility Survey, the independent variable is growth in GDP per

\footnotetext{
${ }^{11}$ For countries where data from 1960 and/or 1992 was not available, we computed growth rates over the closest available interval.
} 


\begin{tabular}{cclcccc}
\hline \hline Sample & Observations & Variable & Mean & S.D. & Min & Max \\
\hline 1960-1976 & 40 & GR & 1.95 & 3.65 & -5.75 & 8.44 \\
& & GINI & 44.32 & 11.14 & 23.38 & 68.00 \\
& & TFR & 5.56 & 1.89 & 2.02 & 7.93 \\
& & DTFR & 2.23 & 1.56 & 0.22 & 5.30 \\
$1976-1992$ & \multirow{3}{*}{43} & GR & 0.39 & 1.89 & -3.46 & 4.97 \\
& & GINI & 45.91 & 9.56 & 28.90 & 69.00 \\
& & TFR & 6.06 & 1.08 & 3.37 & 8.00 \\
& & DTFR & 2.41 & 0.99 & 0.10 & 4.50 \\
Total & \multirow{3}{*}{83} & GR & 1.14 & 2.97 & -5.75 & 8.44 \\
& & GINI & 45.14 & 10.32 & 23.38 & 69.00 \\
& & TFR & 5.82 & 1.54 & 2.02 & 8.00 \\
& & DTFR & 2.32 & 1.29 & 0.10 & 5.30 \\
\hline
\end{tabular}

Table 2: Descriptive Statistics

capita in the first period, and for countries that participated in the Demographic and Health Surveys the left-hand side variable is growth over the second period. Our differential fertility variable DTFR is the difference in the total fertility rate between women with the highest and the lowest education level. For some countries we have two observations from the Demographic and Health Surveys, in which case we averaged the two resulting values. For 25 countries we have only observations for the first period, for 28 countries we have only observations for the second period, and for 15 countries there are observations from both periods.

The remaining independent variables are initial GDP per capita (GDP), the average ratio of investment to GDP (I/GDP), the average ratio of government expenditure to GDP (G/GDP), the initial Gini coefficient for the income distribution (GINI), a dummy variable for African countries (AFR), and the initial total fertility rate (TFR). I/GDP and G/GDP are from the Penn World Tables, the income Ginis are from Deininger and Squire (1996), and total fertility rates and life expectancy (which is used as an instrument) are from the Barro-Lee data set. ${ }^{12}$ The inclusion of initial GDP

\footnotetext{
${ }^{12}$ Where possible, the Gini coefficients are from the initial year; otherwise we used the closest avail-
} 
and the investment ratio is important to control for transitional dynamics.

One shortcoming of the data set is that the observations on fertility differentials are close to the end of the period over which we compute growth rates. Since the fertility observations are five-year averages and result from decisions and actions taken even earlier, the endogeneity problem is not too severe. We correct for potential endogeneity of the differentials by using instrumental variables.

Table 2 provides descriptive statistics for the main variables in our analysis. The two sub-samples are similar, except that the average growth rate is much lower in the second sample. Since we will allow for different constant terms in the two subsamples, this difference will not play a role in the results. These will thus reflect crosssectional differences among countries, as well as variation over time within countries.

\subsection{Estimation Results}

Table 3 contains our estimation results. In all cases, the left-hand side variable is the average growth rate of GDP per capita. The regression equation is estimated with the Generalized Method of Moments. For countries that are present in both sample periods, we allow the error term to be correlated across the periods, and we use instrumental variables to correct for possible endogeneity of I/GDP, G/GDP, GINI, and DTFR. We allow the constant to differ across the periods (Constant A for the early period and Constant $\mathrm{B}$ for the late period). Our regressions are designed to be comparable to Barro (2000), but we include fewer variable because of the small sample size. Regression (1) reproduces standard results in the growth regression literature: the investment rate has a positive effect, whereas the government share, initial GDP, and the African dummy have negative effects on growth. Regression (2) adds the Gini coefficient. The estimated coefficient is significantly negative, and its value is close to Barro's estimate. The value of the parameter implies that an increase in the Gini of 0.4 (roughly the range of variation in the data) lowers growth by about $1.2 \%$ per year. However, when the total fertility rate is included (regression 3), the coefficient

able year. For a few countries, no data is available in Deininger and Squire (1996). For Benin, Burundi, Central Africa, and Namibia, we relied on the "Economic Report on Africa 1999: The Challenges of Poverty Reduction and Sustainability", United Nations. For Haiti and Syria, only land Ginis from (Jazairy, Alamgir, and Panuccio 1992) are available. We regressed the available income Ginis on the land Ginis (correlation: 0.61) and used the predicted values. 


\begin{tabular}{|c|c|c|c|c|c|c|c|c|}
\hline \multirow{3}{*}{$\begin{array}{l}\text { Independent } \\
\text { variable } \\
\text { Constant A }\end{array}$} & \multicolumn{8}{|c|}{ Regression } \\
\hline & \multicolumn{2}{|c|}{ (1) } & \multicolumn{2}{|c|}{ (2) } & \multicolumn{2}{|c|}{ (3) } & \multicolumn{2}{|c|}{ (4) } \\
\hline & $12.35^{\star \star}$ & $(1.31)$ & $12.79^{\star \star}$ & (1.33) & $15.30^{\star \star}$ & $(1.46)$ & $13.92^{\star \star}$ & (1.69) \\
\hline Constant B & $10.41^{\star \star}$ & $(1.36)$ & $10.98^{\star \star}$ & (1.38) & $13.40^{\star \star}$ & $(1.45)$ & $12.18^{\star \star}$ & (1.63) \\
\hline $\ln (\mathrm{GDP})$ & $-1.33^{\star \star}$ & $(0.17)$ & $-1.21^{\star \star}$ & $(0.16)$ & $-1.37^{\star \star}$ & $(0.15)$ & $-1.55^{\star \star}$ & $(0.20)$ \\
\hline I/GDP & $0.14^{\star \star}$ & $(0.02)$ & $0.13^{\star \star}$ & $(0.02)$ & $0.07^{\star \star}$ & $(0.03)$ & $0.08^{\star \star}$ & $(0.04)$ \\
\hline G/GDP & $-0.08^{\star \star}$ & $(0.03)$ & $-0.07^{\star \star}$ & $(0.03)$ & $-0.05^{\star}$ & $(0.03)$ & $-0.05^{\star}$ & $(0.03)$ \\
\hline AFR & $-1.75^{\star \star}$ & $(0.35)$ & $-1.80^{\star \star}$ & $(0.35)$ & $-1.95^{\star \star}$ & $(0.32)$ & $-2.41^{\star \star}$ & $(0.44)$ \\
\hline GINI & & & $-0.03^{\star \star}$ & $(0.01)$ & 0.02 & $(0.03)$ & 0.06 & $(0.05)$ \\
\hline $\ln (\mathrm{TFR})$ & & & & & $-1.84^{\star \star}$ & $(0.87)$ & -1.01 & (1.01) \\
\hline $\ln$ (DTFR) & & & & & & & $-1.22^{\star \star}$ & $(0.50)$ \\
\hline$J_{\text {test }}$ & 17.71 & {$[0.48]$} & 17.11 & [0.45] & 16.79 & [0.40] & 9.58 & [0.85] \\
\hline$L R_{1}$ & & & & & & & 5.53 & [0.01] \\
\hline$L R_{2}$ & & & & & & & 2.08 & [0.35] \\
\hline
\end{tabular}

The dependent variable is the growth rate of real per capita GDP. Estimation by GMM. The instruments are: constant, log of initial GDP per capita, log of initial GDP per capita squared, initial investment/GDP ratio, initial government spending/GDP ratio, initial fertility, initial fertility squared, initial life expectancy, initial life expectancy squared, Africa dummy, and the tropics and access to the sea variables of Sachs and Warner (1997).

Standard errors are reported in parentheses. These are based on the heteroscedastic-consistent covariance matrix of Newey-West. One star indicates significance at the $10 \%$, two stars indicate significance at the $5 \%$ level.

$J_{\text {test }}$ is the test for over-identifying restrictions of Hansen (1982), asymptotically $\chi^{2}$ distributed with $n$ degrees of freedom, where $n$ is the number of over-identifying restrictions. Corresponding $p$-values are reported in brackets.

$L R_{1}$ is a quasi-likelihood ratio test for the absence of the differential fertility in the equation. $L R_{2}$ is the test for the absence of both Gini and total fertility. As suggested by Gallant (1987), they are computed as the normalized difference between the constrained objective function and the unconstrained one. The constrained estimation is computed with the weighting matrix provided by the unconstrained estimation. The corresponding $p$-values are reported in brackets.

Table 3: Generalized Method of Moments Estimation 


\begin{tabular}{lcccccccc}
\hline \multirow{2}{*}{$\begin{array}{l}\text { Independent } \\
\text { variable }\end{array}$} & \multicolumn{9}{c}{$(1)$} & \multicolumn{9}{c}{$(2)$} & \multicolumn{3}{c}{$(3)$} & \multicolumn{3}{c}{$(4)$} \\
\cline { 2 - 10 } Constant A & 9.88 & $(10.1)$ & -6.70 & $(17.5)$ & -3.31 & $(18.8)$ & 6.72 & $(19.9)$ \\
Constant B & 7.95 & $(10.1)$ & -8.48 & $(17.4)$ & -4.77 & $(18.6)$ & 479 & $(19.7)$ \\
$\ln (\mathrm{GDP})$ & -0.65 & $(2.73)$ & 4.65 & $(4.12)$ & 2.37 & $(4.09)$ & 1.39 & $(4.26)$ \\
$\ln (\mathrm{GDP})^{2}$ & -0.04 & $(0.18)$ & -0.40 & $(0.24)$ & -0.15 & $(0.20)$ & -0.26 & $(0.22)$ \\
$\mathrm{I} / \mathrm{GDP}$ & $0.14^{\star \star}$ & $(0.02)$ & $0.10^{\star \star}$ & $(0.02)$ & $0.07^{\star}$ & $(0.04)$ & $0.08^{\star \star}$ & $(0.04)$ \\
$\mathrm{G} / \mathrm{GDP}$ & $-0.08^{\star \star}$ & $(0.03)$ & $-0.08^{\star \star}$ & $(0.03)$ & $-0.07^{\star \star}$ & $(0.04)$ & $-0.07^{\star \star}$ & $(0.03)$ \\
$\mathrm{AFR}$ & $-1.73^{\star \star}$ & $(0.36)$ & $-1.64^{\star \star}$ & $(0.46)$ & $-2.23^{\star \star}$ & $(0.43)$ & $-2.10^{\star \star}$ & $(0.52)$ \\
$\mathrm{GINI}$ & & & -0.13 & $(0.22)$ & 0.31 & $(0.27)$ & -0.18 & $(0.37)$ \\
$\ln (\mathrm{GDP})^{\star} \mathrm{GINI} / 100$ & & & -0.01 & $(0.03)$ & -0.04 & $(0.04)$ & 0.03 & $(0.05)$ \\
$\ln (\mathrm{TFR})$ & & & & & $-2.20 *$ & $(1.13)$ & 0.14 & $(1.51)$ \\
$\ln (\mathrm{DTFR})$ & & & & & & & $-1.56^{\star \star}$ & $(0.68)$ \\
\hline$J_{\text {test }}$ & 17.63 & {$[0.41]$} & 13.87 & {$[0.54]$} & 16.58 & {$[0.28]$} & 8.38 & {$[0.82]$} \\
$L R_{1}$ & & & & & & & 5.54 & {$[0.02]$} \\
$L R_{2}$ & & & & & & & 0.52 & {$[0.77]$} \\
\hline
\end{tabular}

The dependent variable is the growth rate of real per capita GDP. Estimation by GMM. Instruments as in Table 3.

Table 4: GMM Estimation with Squared GDP and Cross Effects 
on the Gini coefficient changes sign and becomes insignificant, which is also in line with Barro (2000).

Regression (4) includes the differential-fertility variable. The coefficient on differential fertility is significantly negative. The point estimate implies that an increase in the fertility differential from one to two would lower growth by $0.8 \%$ per year. With differential fertility included, the coefficients on both Gini and TFR are insignificant, and the point estimate on the Gini is positive.

Based on the results in Section 4, our model predicts that Gini, total fertility, and differential fertility should all be equally negatively related to growth. It is therefore not clear why the coefficients on the Gini and the total fertility rate become insignificant once differential fertility is introduced. One possibility is that inequality and total fertility are influenced by other factors which do not affect growth, while differential fertility is observed with less noise. A second possibility is that total fertility and inequality have other effects on growth, which are not present in our model and do not work through differential fertility. If some of these effects on growth are positive and therefore offset the negative effects, it would be plausible that the overall effect of total fertility and the Gini becomes insignificant once the differential-fertility channel is controlled for.

Hansen's J-test measures how close the residuals are to being orthogonal to the instrument set. It can be seen as a global specification test. The degrees of freedom equal the number of restrictions imposed by the orthogonality conditions. These restrictions are never rejected at the $5 \%$ level. Moreover, there is a large improvement in the value of the test when differential fertility is introduced. The significance of the differential fertility variable is verified both by its $t$-statistic and by the quasilikelihood ratio test $L R_{1}$. The test $L R_{2}$ of joint insignificance of GINI and TFR is not rejected.

Barro (2000) argues that there are important non-linear effects that relate the levels of development and inequality to growth rates. He shows that unless these nonlinear effects are addressed, the effects of inequality and fertility on growth are difficult to distinguish. To check whether our findings are robust with respect to the inclusion of non-linear terms, we add a squared term for GDP per capita and an interaction term involving GDP and inequality to the explanatory variables. Table 4 presents the results. The new terms are never significant and do not affect the significance 
of the J-tests. Given our relatively small number of observations, the inclusion of additional variables lowers the significance of the other variables. In particular, the Gini coefficient is now never significant, but total fertility is significant in regression (3). Our main conclusion remains: when differential fertility is added in regression (4), it is significant, while total fertility is not. Differential fertility again improves the value of the J-test. ${ }^{13}$

In summary, we find that standard growth regressions detect the effect of differential fertility on growth postulated by our model. The effects implied by the regressions are sizable. At the same time, including differential fertility leaves the direct effect of the Gini coefficient insignificant, with a positive point estimate.

\section{Conclusion}

Most of the theoretical literature on inequality and growth has concentrated on channels where inequality affects growth through the accumulation of physical capital. In this paper we propose a different mechanism which links inequality and growth through differential fertility and the accumulation of human capital. In our model, families with less human capital decide to have more children and invest less in education. When income inequality is high, large fertility differentials lower the growth rate of average human capital, since poor families who invest little in education make up a large fraction of the population in the next generation. A calibration exercise shows that these effects can be fairly large. In the benchmark case, raising the Gini from 0.2 to 0.65 lowers the initial annual growth rate by $1.4 \%$. We also examine the role of differential fertility in the growth-regression framework used, among others, by Perotti (1996) and Barro (2000). In line with the predictions of the theory, we find sizable negative effects of differential fertility on growth. Both the empirical results and the quantitative analysis of the model suggest that the differential-fertility channel is important for accounting for the cross-sectional relationship between inequality and growth.

\footnotetext{
${ }^{13}$ As an additional test of the robustness of our results, we also carried out regressions with initial life expectancy as an explanatory variable. Growth regressions generally show life expectancy to be more closely related to growth than other demographic variables such as the total fertility rate. However, even if we add life expectancy to regression (4) in Table 3, differential fertility continues to have a significantly negative effect on growth, albeit with a lower point estimate of -0.79 .
} 
We also examine the time series implications of our model for the joint evolution of inequality, fertility, and growth. Since in our overlapping-generations model a period is one generation, the dynamics of the model are to be interpreted as changes which occur over a horizon of a century or more. Here we find that the model is able to explain key features of the evolution of income, fertility, and inequality in industrializing countries in the last 200 years. Specifically, the model generates an initial increase and ultimate decline in inequality and fertility. The same pattern has been observed in many industrializing countries in the 19th and early 20th centuries. In addition, if we specify the model to allow for endogenous growth, the model generates steadily increasing growth rates throughout the transition, which is another stylized feature of the data.

Our analysis provides a new perspective on the link between economic growth and population growth. Existing studies have found little correlation between the growth rates of population and output per capita (see Kelley and Schmidt 1999), which has led some researchers to conclude that population does not matter for growth. The results in this paper suggest that it is not overall population growth, but the distribution of fertility within the population which is important. In other words, who is having the children matters more than how many children there are overall.

A natural direction for further research concerns the policy implications of our model. Since differential fertility rather than inequality per se is the main source of growth effects, it is not clear that redistributional policies would increase economic growth. Indeed, a typical outcome in models with endogenous fertility is that income redistribution tends to increase fertility differentials (see Knowles 1999), which would lower the growth rate. Here the policy implications of our model are in stark contrast to other theories linking inequality and growth. Compared to income redistribution, policies aimed at equalizing access to education would be more effective. 


\section{References}

Acemoglu, Daron and Joshua D. Angrist. 2000. "How Large are Human Capital Externalities? Evidence from Compulsory Schooling Laws." NBER Macroeconomics Annual 2000, pp. 9-59.

Althaus, Paul G. 1980. "Differential Fertility and Economic Growth." Zeitschrift für die gesamte Staatswissenschaft 136:309-326.

Angrist, Joshua D. and Alan B. Krueger. 1991. "Does Compulsory School Attendance Affect Schooling and Earnings?" The Quarterly Journal of Economics 106 (4): 979-1014.

Ashenfelter, Orley and Alan B. Krueger. 1994. "Estimates of the Economic Return to Schooling from a New Sample of Twins." American Economic Review 84:1157-73.

Barro, Robert J. 2000. "Inequality and Growth in a Panel of Countries." Journal of Economic Growth 5:5-32.

Becker, Gary S. and Robert J. Barro. 1988. "A Reformulation of the Economic Theory of Fertility." Quarterly Journal of Economics 103:1-25.

Bénabou, Roland. 1996. "Inequality and Growth." NBER Macroeconomics Annual, pp. 11-74.

Boucekkine, Raouf, David de la Croix, and Omar Licandro. 2002. "Vintage Human Capital, Demographic Trends, and Endogenous Growth." Journal of Economic Theory 104 (2): 340-75.

Card, David and Alan B. Krueger. 1996. "School Resources and Student Outcomes: An Overview of the Literature and New Evidence from North and South Carolina." Journal of Economic Perspectives 10 (4): 31-50.

Chesnais, Jean Claude. 1992. The Demographic Transition. Oxford: Oxford University Press.

Dahan, Momi and Daniel Tsiddon. 1998. "Demographic Transition, Income Distribution, and Economic Growth." Journal of Economic Growth 3 (March): 29-52.

Deininger, Klaus and Lyn Squire. 1996. “Measuring Income Inequality: A New Database." Development Discussion Paper No. 537, Harvard Institute for International Development. 
Doepke, Matthias. 2001. "Accounting for Fertility Decline During the Transition to Growth." Working Paper No. 804, UCLA Department of Economics.

Gallant, Donald. 1987. Nonlinear Statistical Models. John Wiley \& Sons.

Galor, Oded and David N. Weil. 2000. "Population, Technology, and Growth: From Malthusian Stagnation to the Demographic Transition and Beyond." American Economic Review 90 (4): 806-28.

Galor, Oded and Hyoungsoo Zang. 1997. "Fertility, Income Distribution, and Economic Growth: Theory and Cross-Country Evidence." Japan and the World Economy 9:197-229.

Glomm, Gerhard and B. Ravikumar. 1992. "Public Versus Private Investment in Human Capital: Endogenous Growth and Income Inequality." Journal of Political Economy 100 (4): 818-834.

Hansen, Lars P. 1982. "Large sample properties of generalized method of moments estimators." Econometrica 50:1029-1054.

Hansen, Gary D. and Edward C. Prescott. 1999. "Malthus to Solow." Federal Reserve Bank of Minneapolis Staff Report 257.

Haveman, Robert and Barbara Wolfe. 1995. "The Determinants of Children's Attainments: A Review of Methods and Findings." Journal of Economic Literature 33:1829-78.

Jazairy, Idriss, Mohiuddin Alamgir, and Theresa Panuccio. 1992. The State of World Rural Poverty: An Inquiry Into Its Causes and Consequences. New York: New York University Press.

Jones, Elise F. 1982. Socio-Economic Differentials in Achieved Fertility. World Fertility Survey Comparative Studies No. 21. Voorburg, Netherlands: International Statistics Institute.

Kelley, Allen C. and Robert M. Schmidt. 1999. "Economic and Demographic Change: A Synthesis of Models, Findings, and Perspectives." Duke University Department of Economics Working Paper No. 99/01.

Knowles, John. 1999. “Can Parental Decisions Explain U.S. Income Inequality?" Working Paper, University of Pennsylvania. 
Kremer, Michael and Daniel Chen. 2000. "Income Distribution Dynamics with Endogenous Fertility." NBER Working Paper 7530.

Krueger, Alan B. and Mikael Lindahl. 2001. "Education and Growth: Why and for Whom?" Journal of Economic Literature 39 (1): 1101-36.

Leibowitz, Arleen. 1974. "Home Investments in Children." Journal of Political Economy 82:S111-S131.

Maddison, Angus. 2001. The World Economy: A Millennial Perspective. Paris: OECD.

Mboup, Gora and Tulshi Saha. 1998. Fertility Levels, Trends, and Differentials. Demographic and Health Surveys Comparative Studies No. 28. Calverton, Md: Macro International.

Morand, Olivier F. 1999. "Endogenous Fertility, Income Distribution, and Growth." Journal of Economic Growth 4:331-349.

Perotti, Roberto. 1996. "Growth, Income Distribution, and Democracy: What the Data Say." Journal of Economic Growth 1 (2): 149-87.

Psacharopoulos, George. 1994. "Returns to Investment in Education: A Global Update." World Development 22 (9): 1325-43.

Rangazas, Peter. 2000. "Schooling and Economic Growth: A King-Rebelo Experiment with Human Capital." Journal of Monetary Economics 46:397-416.

Rosenzweig, Mark R. and Kenneth I. Wolpin. 1994. "Are There Increasing Returns to the Intergenerational Production of Human Capital." Journal of Human Resources 29:670-93.

Sachs, Jeffrey and Andrew Warner. 1997. "Fundamental Sources of Long-Run Growth." American Economic Review Papers and Proceedings 87:184-188.

United Nations. 1987. Fertility Behaviour in the Context of Development: Evidence from the World Fertility Survey. Population Studies No. 100. New York: United Nations.

_. 1995. Women's Education and Fertility Behavior. New York: United Nations.

Wiggins, Stephen. 1990. Introduction to Applied Nonlinear Dynamic Systems and Chaos. Springer-Verlag.

Williamson, Jeffrey G. 1985. Did British Capitalism Breed Inequality? Boston: Allen and Unwin. 


\section{A Proof of Proposition 1}

Case $\kappa=1-\tau$ : The constant values $g_{t}=B(\eta(\phi-\theta) /(1-\eta))^{\eta}, N_{t}=n_{t}=N^{\star}, x_{t+1}=x_{t}=1$, and:

$$
k_{t+1}=k_{t}=\left(\frac{A \beta(1+\beta+\gamma)(1-\alpha)(\phi-\theta)^{1-\eta}}{B \gamma(1+\beta) \eta^{\eta}(1-\eta)^{1-\eta}}\right)^{\frac{1}{1-\alpha}},
$$

solve equations (16), (17), (18), (20), (21) and (23).

Case $\kappa \neq 1-\tau$ : The constant values $g_{t}=1+\rho, N_{t}=n_{t}=N^{\star}, x_{t+1}=x_{t}=1$,

$$
\hat{h}=\left(\frac{B}{1+\rho}\left(\frac{\eta(\phi-\theta)}{1-\eta}\right)^{\eta}\right)^{\frac{1}{1-\kappa-\tau}}
$$

and:

$$
k_{t+1}=k_{t}=\left(\frac{\beta(\phi-\theta)(1+\beta+\gamma) A(1-\alpha)}{(1+\beta)(1+\rho)(1-\eta) \gamma}\right)^{\frac{1}{1-\alpha}},
$$

solve equations (16), (17), (18), (20), (21) and (23).

\section{B Analysis of the Individual Transition Function}

In order to understand the dynamics of the model, we examine the function $x_{t+1}-x_{t}=$ $\Psi\left(x_{t} ; \tau\right)$, i.e., the change in $x_{t}$ as a function of $x_{t}$ and $\tau$ :

$$
\Psi(x ; \tau)=\frac{B x^{\tau}}{g^{\star}}\left(\theta+\max \left[0, \frac{\eta \phi x-\theta}{1-\eta}\right]\right)^{\eta}\left(\hat{h}^{\star}\right)^{\kappa+\tau-1}-x .
$$

Here $g^{\star}$ and $\hat{h}^{\star}$ are the balanced-growth-path values. In the case $\kappa=1-\tau$ we replace $g^{\star}$ by $B(\eta(\phi-\theta) /(1-\eta))^{\eta}$. In the case $\kappa \neq 1-\tau$, we replace $g^{\star}$ by $1+\rho$ and $\hat{h}^{\star}$ by $\left(\frac{B}{1+\rho}\left(\frac{\eta(\phi-\theta)}{1-\eta}\right)^{\eta}\right)^{\frac{1}{1-\kappa-\tau}}$. Both substitutions lead to the same expression, i.e. equation (24) of the main text. The expression can be rewritten as:

$$
\Psi(x ; \tau)=x^{\tau}\left(\frac{\theta(1-\eta)}{\eta(\phi-\theta)}+\max \left[0, \frac{\eta \phi x-\theta}{\eta(\phi-\theta)}\right]\right)^{\eta}-x .
$$

We first consider the limits of this function. We have: $\Psi(0 ; \tau)=0$ and $\Psi_{x}^{\prime}(0 ; \tau)=+\infty$, and:

$$
\lim _{x \rightarrow \infty} \Psi(x ; \tau)=x^{\tau+\eta}\left(\frac{\phi}{\phi-\theta}\right)^{\eta}-x
$$


which implies:

$$
\lim _{x \rightarrow \infty} \Psi(x ; \tau)=-\infty \text { if } \tau+\eta<1 \text { and } \lim _{x \rightarrow \infty} \Psi(x ; \tau)=+\infty \text { otherwise. }
$$

Hence the function $\Psi$ starts from $(0,0)$ with an infinite slope and goes either to $-\infty$ or $+\infty$ depending on parameter values.

By definition of the aggregate balanced growth path, $x=1$ is a steady state and thus $\Psi(1 ; \tau)=$ 0 . This steady state is locally stable if and only if $\Psi_{x}^{\prime}(1 ; \tau)<0$, i.e.:

$$
\tau+\frac{\eta \phi}{\phi-\theta}-1<0
$$

At the point:

$$
\hat{\tau}=1-\frac{\eta \phi}{\phi-\theta}
$$

the dynamics of individual capital described by: $x_{t+1}-x_{t}=\Psi\left(x_{t} ; \tau\right)$ undergo a transcritical bifurcation, as proved in Proposition 2. There are thus two steady-state equilibria, 1 and $\bar{x}$, near $(1, \hat{\tau})$ for each value of $\tau$ smaller or larger than $\hat{\tau}$. The equilibrium 1 (resp. $\bar{x}$ ) is stable (resp. unstable) for $\tau<\hat{\tau}$ and unstable (resp. stable) for $\tau>\hat{\tau}$.

Another point of interest is $x_{t}=\frac{\theta}{\eta \phi}$. If, at this point, the function $\Psi$ is negative, it crosses the horizontal axes between 0 and $\frac{\theta}{\eta \phi}$. The existence of this steady state results from the infinite slope of $\Psi$ at 0 and from its continuity; uniqueness results from the concavity of the function in the interval $\left(0, \frac{\theta}{\eta \phi}\right)$. We evaluate:

$$
\Psi\left(\frac{\theta}{\eta \phi}, \tau\right)=\left(\frac{\theta(1-\eta)}{\eta(\phi-\theta)}\right) \eta\left(\frac{\theta}{\eta \phi}\right)^{\tau}-\frac{\theta}{\eta \phi}
$$

This is negative if $\tau$ is above a threshold $\bar{\tau}$ :

$$
\bar{\tau}=\frac{(1-\eta) \ln (\theta / \eta)-\ln \phi-\eta \ln ((1-\eta) /(\phi-\theta))}{\ln \theta-\ln (\eta \phi)}
$$

We are now able to fully characterize the dynamics of $x$ as a function of the parameter $\tau$. The bifurcation diagram is presented in Figure 2. 